\title{
WHO MONICA Project: What Have We Learned and Where to Go from Here?
}

\author{
Russell V. Luepker, MD, MS ${ }^{1}$
}

\begin{abstract}
The decline in infectious diseases and a rise in chronic diseases, particularly cardiovascular disease (CVD), underlies the health trajectory of the $20^{\text {th }}$ century. While much was known about CVD, particularly myocardial infarction and stroke, population data were problematic. Importantly, the peak and decline of the CVD epidemic in the 1960s and 1970s in some countries was not well recognized, leading to calls for more population-based disease surveillance. The WHO Multinational MONItoring of Trends and Determinants in CArdiovascular Disease (MONICA) Project was the most comprehensive approach to better understanding disease etiology, incidence and trends at the population level. For a period of ten years or more in each center, from the early 1980s to the mid 1990s, MONICA implemented CVD surveillance in 21 countries. It included mortality, morbidity, coronary care, and population-based risk factor surveillance. The study is characterized by welldescribed methods and high quality data. The findings show large differences between different centers in 21 countries and provide information for disease treatment and prevention. Many MONICA centers continued to actively collect data on populations within their countries. This experience provides a comprehensive approach for CVD patterns in the developed countries and the oncoming epidemic in the developing world.
\end{abstract}

Keywords: Cardiovascular diseases, coronary care, coronary risk factors, disease surveillance, epidemiologic methods, international studies

Recommended Citation: Luepker RV. WHO MONICA project: what have we learned and where to go from here? Public Health Reviews. 2012;33:373-96.

\footnotetext{
${ }^{1}$ Mayo Professor, Division of Epidemiology and Community Health, School of Public Health, University of Minnesota

Corresponding Author Contact Information: Russell V. Luepker at luepker@epi.umn.edu; Division of Epidemiology and Community Health, School of Public Health, University of Minnesota, 1300 S. Second St., Suite 300, Minneapolis, MN 55454
} 


\section{INTRODUCTION}

The health trajectory of the $20^{\text {th }}$ century is characterized by a decline in infectious diseases and a rise in life expectancy. Longer lives, coupled with increasing age-related incidence, resulted in increases in chronic diseases, particularly cardiovascular diseases (CVDs), becoming the leading causes of morbidity and mortality among adults in the industrialized world. That epidemiologic transition to chronic diseases is now occurring in developing countries. While clinicians were well aware of common diseases in their practice, epidemiologists were slow to note the rise and subsequent fall of CVD. This was first noted in a systematic way in the United States at the Bethesda Conference in $1978 .{ }^{1}$ In that year, it was already apparent that the CVD epidemic had peaked in the US in the 1960s when age-adjusted mortality began to fall.

The origins of the CVD epidemic was studied for many years in the groundbreaking Framingham and Seven Countries studies. ${ }^{2,3}$ In addition to developing methods for surveillance of selected populations, these early studies demonstrated the importance of risk factors in the etiology of the major CVDs. However, the highly selected populations in these studies did not lead to a necessary understanding of population disease patterns elsewhere.

The 1978 Bethesda conference emphasized the need to develop surveillance systems to better understand disease trends in specific and national populations. ${ }^{1}$ In the US, a number of programs were initiated, some strictly surveillance $e^{4,5}$ and some associated with population-based prevention studies..$^{6-8}$ Each of these studies contained population-based surveys, hospital morbidity registration and mortality data.

Also stimulated by the Bethesda Conference, a similar and much larger effort began through the World Health Organization (WHO) Headquarters in Geneva, Switzerland, to bring together those interested in a multinational collaborative study. Multinational MONItoring of Trends and Determinants in CArdiovascular Disease, known as the WHO MONICA Project, aimed to study trends in coronary heart disease events, coronary care, stroke, and risk factorsin multiple defined geographical populations, contemporaneously across the world. ${ }^{9}$ MONICA began in 1979 and enrolled investigators from 26 countries, of which 21 completed the full study. MONICA took place mainly in Europe, but included centers in the US, Canada, China and Australasia. The task was enormous - collection of ten years of standardized data in areas of varying resources and disease patterns. That MONICA succeeded in collecting quality data is a tribute to the sponsors and investigators. The methods are still used and applicable today and many of the centers continue this work, confirming MONICA's importance. 
While CVDs are declining in many industrialized nations, they continue to be leading causes of morbidity and mortality. In addition, the widespread application of sophisticated technologies, from new drugs to heart transplants, has led to increasing healthcare resources devoted to these diseases. These and other factors reinforce the need for quality surveillance, such as that initiated by MONICA. A recent report from the US Institute of Medicine reinforces the need for CVD surveillance. ${ }^{10}$ The following is a brief overview of MONICA, reviewing the strategies and outcomes from this unique surveillance project.

\section{BACKGROUND}

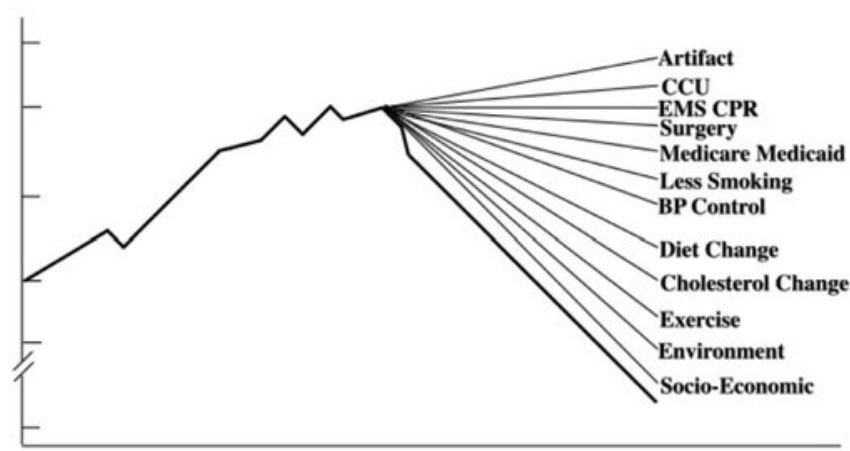

Fig. 1. Causes of the Decrease in Cardiovascular Mortality. Can we identify factors causing the coronary mortality rate decrease and measure their contribution? $\mathrm{BP}=$ blood pressure; $\mathrm{CCU}=$ cardiopulmonary resuscitation; $\mathrm{EMS}=$ emergency medical service.

Source: Reprinted from American Journal of Cardiology, vol. 54, Levy RI, Causes of the decrease in cardiovascular mortality, pages 7C-13C, 1984, with permission from Elsevier. ${ }^{64}$

The observation of an emerging epidemic and subsequent declining pattern raised many questions. Where were the trends going? How did they affect different populations? What were the causes (Figure 1)? A number of cohort studies had been undertaken in the 1950s and 1960s including the Framingham Study, the Tecumseh Michigan Study and the Puerto Rican Heart Study. ${ }^{2,11,12}$ These projects were aimed at determining the causes of CVD focusing on healthy people and followed them forward for disease events, they did not study population trends. Only Framingham continues today. ${ }^{2}$ In the same era 
of the 1950s, the Seven Countries Study set a standard for multi-center cohort studies. ${ }^{3}$ It was based on the belief that significant differences in disease patterns would be observed between populations that may not be apparent within populations, revealing underlying mechanisms. This study also continues today. In 1969, the WHO Regional Office for Europe initiated a series of community myocardial infarction registers to record population incidence (including coronary deaths) and outcomes. However, these registers were not generally maintained beyond two or three years. ${ }^{13}$ Subsequent to the Bethesda Conference in 1988, there were new observations by Uemura and Pisa showing international trends in cardiovascular mortality in the period following the Second World War confirming large differences between countries. ${ }^{14}$ CVD patterns were definitely changing. Why?

Ten years after the 1978 first Bethesda conference, a second international conference was convened by the National Heart, Lung and Blood Institute (NHLBI) in Bethesda in August 1988 to review progress. ${ }^{15}$ The establishment of several studies in the US ${ }^{4,5}$ and the enhanced capability of the US National Health and Nutrition Examination Survey (NHANES) ${ }^{16}$ began to provide data. These population studies link morbidity and mortality from CVDs with population measurements of risk factors and health behaviors. Community-based Heart Health Programs also added to the information about population trends. ${ }^{17}$

Table 1

MONICA Measures and Hypotheses

MONICA Measurements

\begin{tabular}{l|l}
\hline A. & Incidence rates (fatal [=mortality] and nonfatal events) over ten years \\
\hline B. & Case fatality (percentage fatal at 28 days from onset) over ten years \\
\hline C. & Risk factor levels and trends through repeated population surveys (2 or 3$)$ \\
\hline D. & Medical care on two occasions during surveillance, continuous in some centers \\
\hline
\end{tabular}

Potential Associations of Trends in These Measurements

\begin{tabular}{l|l}
\hline A. & Risk factors and incidence (subject of first null hypothesis on trends) \\
\hline B. & Medical care and case fatality (subject of second null hypothesis on trends) \\
\hline C. & Incidence and case fatality (explored cross-sectionally) \\
\hline D. & Medical care and incidence (incorporated in analyses for second null hypothesis) \\
\hline E. & Risk factors and case fatality (not analyzed so far but now historical data) \\
\hline F. & Medical care and risk factors (not analyzed so far but now historical data) \\
\hline
\end{tabular}


By this time, MONICA collaborators and the US Atherosclerosis Risk in Communities (ARIC) study participants, who had worked together at first, were implementing somewhat different protocols. ${ }^{9}, 18$ Beyond surveillance of disease in defined populations, MONICA employed repeated independent random sample population surveys incorporating a few core risk factors. Meanwhile, ARIC studied a large cohort with many different risk factors measured along with community-based disease surveillance.

MONICA was a comprehensive study examining numerous questions in the international setting with well-controlled, standardized methods. MONICA included core measurements with the goal of testing several hypotheses, primarily on coronary heart disease (Table 1), but also for stroke at some of the study centers. In addition to studies on the core disease patterns and risk factors, there were numerous optional sub-studies initiated by MONICA investigators and follow-up studies on their survey participants. The collaborative MONICA optional studies are shown in Table 2 and there were also many additional locally based optional studies reported by individual centers. ${ }^{9}$

Table 2

MONICA Optional Studies

\begin{tabular}{l|l}
\hline A. & Study on nutrition \\
\hline B. & Study on anti-oxidant vitamins and polyunsaturated fatty acids \\
\hline C. & Psychosocial study \\
\hline D. & Study of physical activity \\
\hline E. & Study of drugs \\
\hline F. & Study on hemostatic risk factors \\
\hline
\end{tabular}

\section{STUDY STRUCTURE}

The MONICA study began in 1979 with organizational meetings at the WHO. Initially, funding for coordination and international travel came from the WHO: individual centers were funded locally from local and central governments, charitable foundations and others. The establishment of the Data Centre in Helsinki at the National Public Health Institute in Finland led to increasing Finnish commitment. The US NHLBI funded quality control work through WHO. Additional funding was obtained from the European Commission and a system was established to accept industry grants. 
The study was led by a council of principal investigators meeting as a group nine times during the 23 years of the study (Table 3 ). They served in the manner of a parliament with oversight for decision-making. A subcommittee, the MONICA Steering Committee, managed the project, having 29 meetings over the years, 116 telephone conferences, and a torrent of e-mail communications as early as 1988. The steering committee contained both elected and ex-officio members. The elected members were selected from the principal investigators at the collaborating sites. The WHO provided the MONICA Management Centre, hosting the early meetings.

\section{Table 3}

MONICA Centers - Principal and Co-Principal Investigators During Data Collection.

\begin{tabular}{l|l}
\hline \multicolumn{1}{c|}{ MONICA Centers } & \multicolumn{1}{c}{ Principal and Co-Principal Investigators } \\
\hline Australia-Newcastle (AUS-NEW, AN) & Stephen Leeder, Annette Dobson \\
\hline Australia-Perth (AUS-PER, AP) & Michael Hobbs, Konrad Jamrozik \\
\hline Belgium-Ghent/Charleroi (BEL-GCH, BE) & Guy De Backer, Marcel Kornitzer \\
\hline Canada-Halifax (CAN-HAL, CA) & $\begin{array}{l}\text { Hermann Wolf, Ronald Gregor, Iqbal Bata, } \\
\text { Ross Mackenzie }\end{array}$ \\
\hline China-Beijing (CHN-BEI, CN) & $\begin{array}{l}\text { Zhaosu Wu, Yingkai Wu, Chonghua Yao, Dong } \\
\text { Zhao }\end{array}$ \\
\hline Czech Republic (CZE-CZE, CZ) & Zdenka Škodová \\
\hline Denmark-Glostrup (DEN-GLO, DN) & Marianne Schroll \\
\hline Finland (FIN-FIN, FI) & Jaakko Tuomilehto, Pekka Puska \\
\hline France-Country Coordinating Centre & Pierre Ducimetière, JL Richard \\
\hline France-Lille (FRA-LIL, FL) & $\begin{array}{l}\text { Philippe Amouyel, Michele Montaye, JL } \\
\text { Salomez, MC Nuttens, G Luc }\end{array}$ \\
\hline France-Strasbourg (FRA-STR, FS) & Dominique Arveiler, Paul Schaffer \\
\hline France-Toulouse (FRA-TOU, FT) & $\begin{array}{l}\text { Jean Ferrières, Jean-Bernard Ruidavets, Jean- } \\
\text { Pierre Cambou }\end{array}$ \\
\hline Germany-Augsburg (GER-AUG, GA) & Ulrich Keil \\
\hline Germany-Bremen (GER-BRE, GB) & $\begin{array}{l}\text { Eberhard Greiser, Katrin Janhsen, Bertram } \\
\text { Herman }\end{array}$ \\
\hline Fom
\end{tabular}


Table 3 Contd.

\begin{tabular}{|c|c|}
\hline MONICA Centers & Principal and Co-Principal Investigators \\
\hline Germany-East Germany (GER-EGE, GE) & Lothar Heinemann, Wolfgang Barth \\
\hline Iceland (ICE-ICE, IC) & $\begin{array}{l}\text { Nikulás Sigfússon, Inga Ingibjörg } \\
\text { Guömundsdóttir }\end{array}$ \\
\hline Italy-Country Coordinating Centre & Simona Giampaoli, Alessandro Menotti \\
\hline Italy-Brianza (ITA-BRI, IT) & Marco Ferrario, Giancarlo Cesana \\
\hline Italy-Friuli (ITA-FRI, IF) & $\begin{array}{l}\text { Diego Vanuzzo, Giorgio Antonio Feruglio, } \\
\text { Lorenza Pilotto }\end{array}$ \\
\hline Lithuania-Kaunas (LTU-KAU, LT) & $\begin{array}{l}\text { Juozas Bluzhas, Stase Domarkiene, Daiva } \\
\text { Rastenyte }\end{array}$ \\
\hline New Zealand-Auckland (NEZ-AUC, NZ) & Robert Beaglehole, Rod Jackson \\
\hline $\begin{array}{l}\text { Poland-Tarnobrzeg Voivodship (POL-TAR, } \\
\text { PT) }\end{array}$ & Andrzej Pajak, Jan Sznajd \\
\hline Poland-Warsaw (POL-WAR, PW) & Stefan Rywik, Grazyna Broda \\
\hline Russia-Moscow (RUS-MOS, RM) & $\begin{array}{l}\text { George Zhukovsky, Sergei Fedotov, Tatyana } \\
\text { Varlamova }\end{array}$ \\
\hline Russia-Novosibirsk (RUS-NOV, RN) & Yuri Nikitin \\
\hline Spain-Catalonia (SPA-CAT, SP) & Susana Sans, Ignacio Balaguer-Vintró \\
\hline Sweden-Gothenburg (SWE-GOT, SG) & Lars Wilhelmsen, Annika Rosengren \\
\hline $\begin{array}{l}\text { Sweden-Northern Sweden (SWE-NSW, } \\
\text { SN) }\end{array}$ & $\begin{array}{l}\text { Kjell Asplund, Torbjorn Messner, Per-Olov } \\
\text { Wester, Fritz Huhtasaari }\end{array}$ \\
\hline Switzerland (SWI-SWI, SW) & $\begin{array}{l}\text { Felix Gutzwiller, Gianfranco Domenighetti, } \\
\text { Fred Paccaud }\end{array}$ \\
\hline United Kingdom-Belfast (UNK-BEL, UB) & Alun Evans \\
\hline $\begin{array}{l}\text { United Kingdom-Glasgow (UNK-GLA, } \\
\text { UG) }\end{array}$ & $\begin{array}{l}\text { Hugh Tunstall-Pedoe, Caroline Morrison, } \\
\text { Cairns Smith, Graham Watt }\end{array}$ \\
\hline United States-Stanford (USA-STA, US) & Stephen Fortmann \\
\hline Yugoslavia-Novi Sad (YUG-NOS, YU) & Milutin Planojevic, Djordje Jakovljevic. \\
\hline
\end{tabular}


In addition to the administrative structures, a number of important functional centers were established. The Helsinki Data Centre was responsible for data quality and management, analysis and archives. Laboratory quality control for lipids, including total cholesterol, HDL cholesterol and thiocyanate (a measure of cigarette smoking), was established in Prague in the Czech Republic. This centre worked in close collaboration with the Lipid Standardization Program at the Centers for Disease Control and Prevention, Atlanta, Georgia. An electrocardiogram (ECG) coding center was established in Budapest, Hungary to implement the Minnesota Code. ${ }^{19}$ Quality control of event registration was centered in Scotland at the University of Dundee which was responsible for the diagnostic algorithms for classifying myocardial infarction and coronary deaths, and for distributing test case histories for coding. Finally, health services data, with standardized measures of medical and surgical care for CVD, was overseen by the University of Western Australia. ${ }^{9}, 20$

The collection of high quality data from multiple centers on four continents with different languages and healthcare systems presented unique challenges. The methods utilized, including MONICA diagnostic criteria and classifications are detailed in the MONICA Manual. ${ }^{18}$ The dedication to quality began with the development of standardized data collection methods followed by training sessions for those collecting the data. Quality control was ongoing and overall quality was evaluated again after the study was finished to test the robustness of the results of data analyses.

\section{POPULATION}

Originally each center was expected to have a population adequate to generate 200 coronary deaths annually in men below age 65. Study populations, defined by geographic boundaries and healthcare delivery patterns, ranged from 100,000 to 1 million population. In all, a population of 10 million was included in the study. The mortality and hospital surveillance were continuous, while the population surveys were the result of independent probability sampling at two to three distinct times over the ten years. There was also an obligatory two periods of recording medical coronary care during the years of surveillance of coronary events. 


\section{DATA COLLECTION AND METHODS}

Mortality was collected from usual sources in each of the communities. However, there were differences in reporting methods which may have resulted in some variability. ${ }^{21-23}$ All CVD deaths, plus ancillary causes which might be CVD, were collected. In addition, other major chronic disease categories including cancer, lung disease and ill-defined conditions were collected as well as all-causes mortality. Mortality trends were followed over the ten years of the study at each center, both for "official trends" from the local death register, not validated; and for trends in validated events subject to MONICA scrutiny and reclassification.

\section{DEMOGRAPHIC DATA}

For each designated geographic population administrative data were sought. This was either based on decennial census data with yearly adjustments or from continuously updated population registers, as practiced, for example, in Scandinavian countries. Resulting numbers were subjected to quality assessment in Helsinki. ${ }^{9}$

\section{CORONARY EVENT REGISTRATION}

Coronary event registration for living cases was focused on hospitals. In different countries, different healthcare systems, regulations and privacy concerns were considered. In addition, all potential cases that did not come to hospital before death, and died out-of-hospital from possible coronary heart disease, were scrutinized and classified using MONICA criteria. MONICA criteria were used to classify death, particularly that from coronary heart disease. ${ }^{18,21,22}$ All MONICA centers extracted a basic dataset with a common protocol.

A variety of data were collected using cold pursuit or hot pursuit. ${ }^{9,18,21}$ These included demographic information, medical and diagnostic data including symptoms, enzymes, electrocardiograms and autopsy findings when performed. ${ }^{21}$ MONICA diagnostic criteria for myocardial infarction and coronary deaths ${ }^{9,18,21}$ were widely used in the 1980s and 1990s, although they have recently been superseded. ${ }^{24}$ 


\section{CORONARY CARE}

Some centers recorded hospital coronary care continuously, but it was obligatory to measure it for two periods during the decade of surveillance. Among many other items, a template for treatment data was included. It involved eight medications and treatments, such as thrombolysis or invasive reperfusion (e.g., angioplasty or coronary artery bypass grafts) including those used before the onset of the attack, during hospitalization, and at discharge from hospital. These data highlighted large differences between centers. ${ }^{25}$

\section{POPULATION SURVEYS}

Free-living populations aged 25- or 35-64 were collected in each MONICA collaborating center. Twelve hundred to 1,600 individuals were required for an adequate sample size. In reality, 1,000-3,000 citizens were selected by independent sampling two or three times over the ten years of the study. Sampling was a single stage or multi-stage procedure. Participation was excellent in most centers with a median of $70-79 \%$ participation, trending downward in many populations over the study decade.

Data collection in the population included major indicators of CVD and demographic information. Smoking was ascertained by interview or selfadministered questionnaire and validated by chemical measurements. Blood pressure was measured manually by a standard sphygmomanometer or a random zero sphygmomanomete ${ }^{26}$ in all the centers. Training of staff, selection of devices and the use of appropriate cuffs were essential to this measure. Blood was collected for total cholesterol and HDL cholesterol. Staff were trained in the appropriate collection and processing methods. Height, weight and waist circumference were measured using standard protocols.

Risk factors were combined in a risk factor score used in the analyses.

\section{DATA CONTROL}

The data were shipped to the MONICA Data Centre in Helsinki. As the study progressed, transmission of event and survey data moved from magnetic tape to floppy disks and finally e-mail, while annual reporting of demographic data and official mortality data began on paper forms. The MONICA Data Centre checked all data for errors and referred questions 
for corrections to the field centers. Data were only changed if the field center agreed. This was partly due to the importance of the source and a policy to allow local control of data from that center for individual analyses. Matching the data in the Data Centre with that of the local center removed disparities in the analytic phase.

Individual reference centers were established for the collaborative optional studies including: the nutrition measures; vitamins and polyunsaturated fatty acid; physical activity; psychosocial factors; drug use prehospital; and hemostatic factors. Data for ancillary studies was analyzed at the reference centers.

\section{MONICA RESULTS}

The MONICA experience resulted in three major publications ${ }^{27-29}$ in the peer-reviewed literature. Collaborative publications can be accessed at the MONICA website, ${ }^{30}$ but there are many more produced by single centers based on their local findings and optional studies. Selected below are some of the major findings involving mortality, coronary events and risk factor changes in 21 countries with 38 populations. It provides a dramatic picture of international differences in CVDs. It is comprehensive in scope and detailed in information. The MONICA database is potentially available for other collaborative analyses, although now becoming a dated resource.

There are several considerations to remember when analyzing the MONICA data. First is the age range, appropriate when the study was designed, of 25- or 35-64 years, when the concern was premature CVD. This age range remains a concern, but much of the disease is now in the older population. Second is the recognition that there are different years for surveillance in the study. Although most of the centers did three surveys over a ten-year period, the calendar years were not identical as different centers entered the study at different times. Therefore, the comparisons detailed below are not always for identical years. Most centers continued to collaborate through years of major international upheaval, including political change in Eastern Europe, and other changes of government, often having to refresh and replace their initial source of funding.

In addition to providing international information on incidence, prevalence and trends, MONICA also contributed substantially to the methodology of population surveillance. This included statistical methods, ${ }^{31,32}$ measurement issues, ${ }^{31-33}$ epidemiologic methods, ${ }^{34-38}$ quality assurance, ${ }^{39,40}$ and diagnostic criteria. ${ }^{18,21}$ 


\section{MORTALITY}

The mortality data from MONICA were extracted from official statistics from each center. The age window for mortality was 35-64 years. Shown in Figure 2 is a comparison of all-cause mortality across the MONICA centers. It includes coronary heart disease, stroke, other CVD and nonCVD. All of the populations are age-adjusted to the 1970s world standard population. ${ }^{41}$ Cardiovascular mortality varied greatly between MONICA sites. There are three to five fold differences between the most affected and those that have the lowest rates. Coronary heart disease, while the commonest single cause of death, contributed a modest fraction of mortality in the 35-64 age group. In all populations, men had significantly higher allcause mortality rates than women, and substantially higher rates for coronary heart disease.
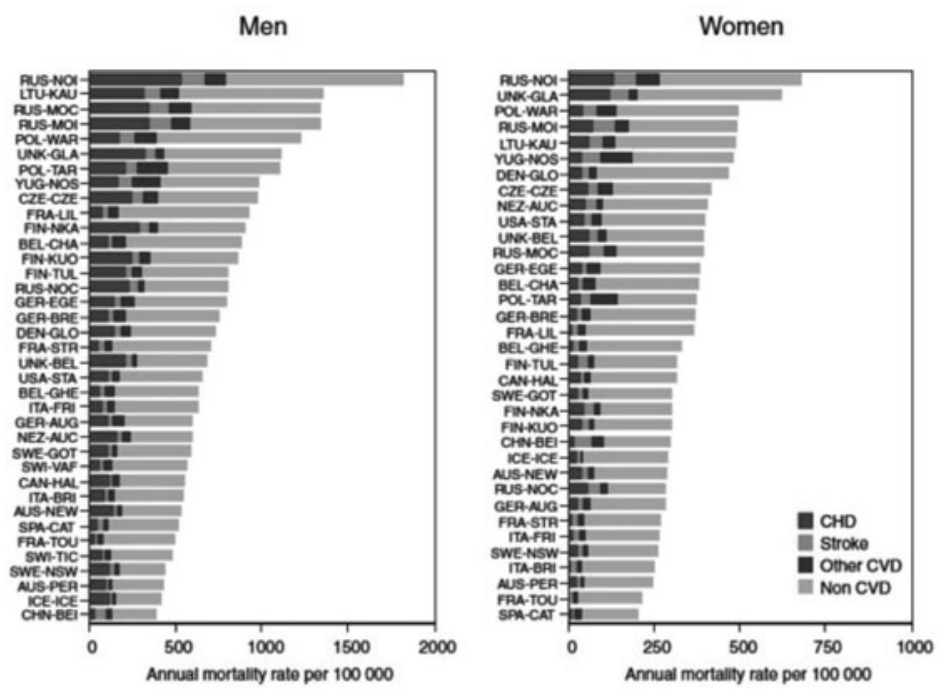

Fig. 2. Death rates (ages 35-64) from various causes: final three years of coronaryevent registration.

Source: MONICA Monograph and Multimedia Sourcebook, $2003 .{ }^{9}$ 


\section{CORONARY EVENT RATES}

MONICA used hospital and mortality registration data from each center for the numerator in event rates. ${ }^{42}$ Demographic data for the denominator was gathered from census. All data were adjusted to the world standard population. ${ }^{41}$ These data are illustrated for the final three years of the study in Figure 3. Again, there are enormous differences between different populations. In men, Glasgow in the United Kingdom and North Karelia in Finland have eight to ten times the coronary event rate of Beijing in China. Similarly, among women, Glasgow has roughly ten times the rate of Beijing and Toulouse in France.
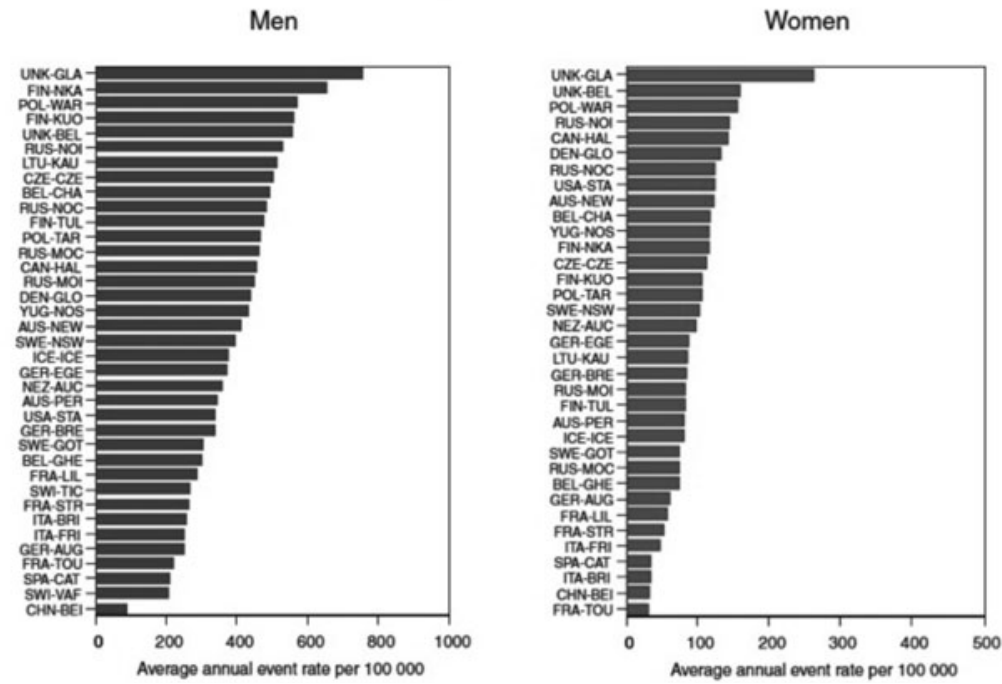

Fig. 3. Coronary-event rates (ages 35-64): final three years of registration.

Source: MONICA Monograph and Multimedia Sourcebook, $2003 .{ }^{9}$

MONICA was primarily a study of trends over time, specifically ten years. In Figure 4, the average annual changes in coronary event rates are depicted. The 95 percent confidence intervals determine the width of the bars. Most populations were tending to an annual decline in event rates, with Finland reporting the largest reduction over time for men. Despite this overall trend, eight of the 38 populations recorded increasing event rates in men. Among women there were also predominantly decreasing event rates with Moscow, Russia and Strasbourg, France having the largest declines but, here again, 12 of the 38 populations saw an increase. 

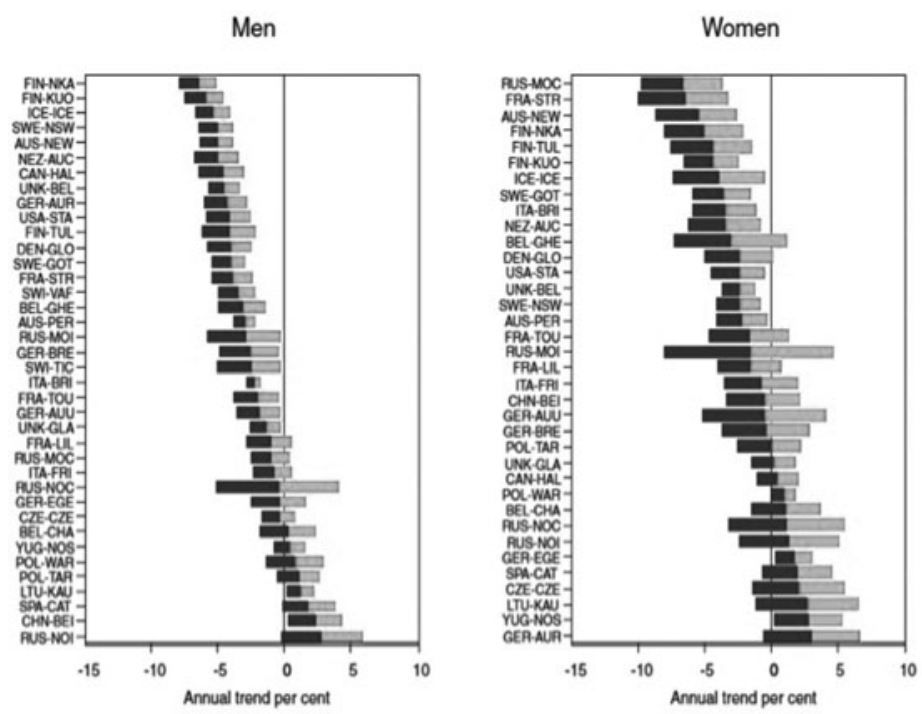

Fig. 4. Average annual change in coronary-event rates.

Source: MONICA Monograph and Multimedia Sourcebook, $2003 .{ }^{9}$

\section{RISK FACTOR SURVEILLANCE}

Each MONICA center identified free-living individuals aged 25- or 35-64 and measured their health status, specifically assessing risk factors for CVD. The major risk factors considered were cigarette smoking, blood pressure, blood cholesterol and body mass index. However, there were other factors considered besides these classical risk factors, both in the entire population and in substudies. The risk factor data are substantial and this review will only touch on two variables: cigarette usage and a risk factor score.

Cigarette usage among men varied greatly between the MONICA centers from a very high rate of use in Beijing to very low rates in Australia, New Zealand and Sweden (Figure 5). Many other countries, particularly those in Eastern Europe, also had very high rates of tobacco use. Among women, smoking rates in all populations were generally lower than in men, the exceptions being those with the highest smoking rates, Glostrup, Denmark and Glasgow, UK, where the rates in men and women were the same. Low rates were reported among women in Lithuania and Russia. 

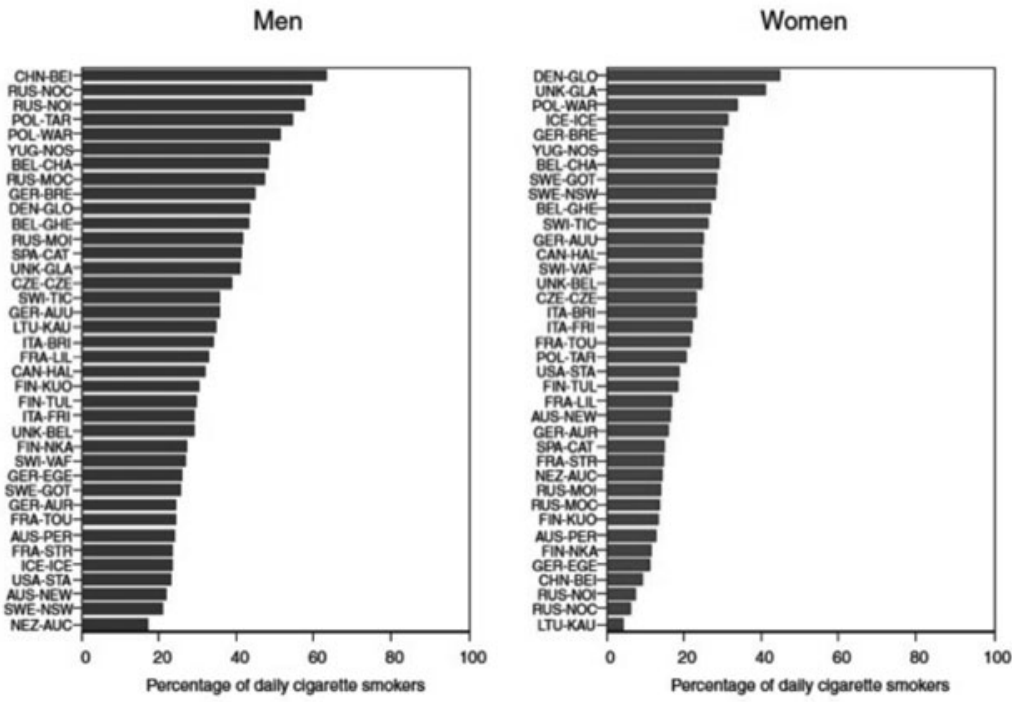

Fig. 5. Prevalence of daily cigarette smokers (ages 25-64) in the final risk-factor survey.

Source: MONICA Monograph and Multimedia Sourcebook, $2003 .{ }^{9}$

Men

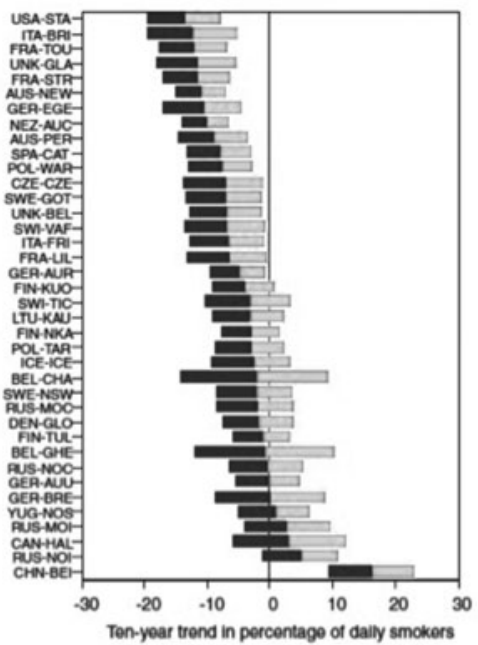

Women

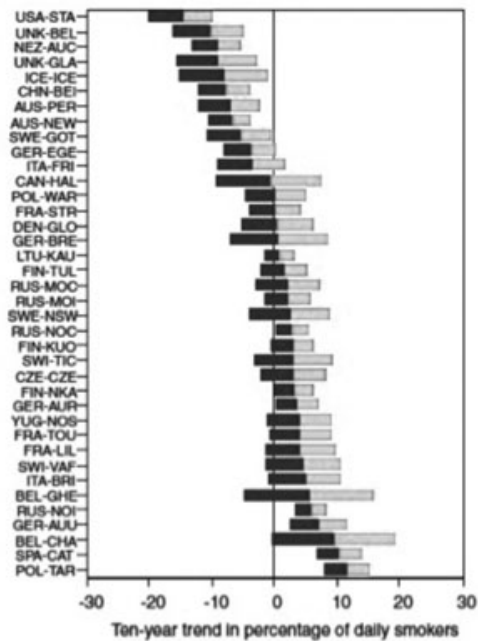

Fig. 6. Ten-year change in prevalence of daily cigarette smokers.

Source: MONICA Monograph and Multimedia Sourcebook, $2003 .{ }^{9}$ 
Trends in daily smoking are quite striking. Most populations experienced declines in the ten-year prevalence of daily cigarette smoking (Figure 6). However, Beijing experienced a substantial increase in the number of men who were daily cigarette smokers, as did several other locations. Among women, cigarette smoking increased in the majority of populations. ${ }^{9}$

The coronary risk factor score was developed for MONICA to summarize the risk factor data collected on individuals. It was derived from Scandinavian cohort studies and emphasized predictors of mortality. The risk score included cigarette smoking, systolic blood pressure, total cholesterol and body mass index. The first three were major contributors to the score but weight, as summarized by body mass index, contributed only modestly. The mean risk score was 6-7.5 in men and 5.7-6.5 in women. As seen in Figure 7, risk scores declined substantially in most populations for both men and women. However, men in Beijing, Yugoslavia and Switzerland demonstrated substantial increases in the coronary risk factor score. Among women, populations in Switzerland, Canada and Yugoslavia also saw significant increases in the risk factor score. The observation that most of the countries saw significant reductions in the risk factor score is important as it is should predict later event rates, although some had a deterioration in scores. ${ }^{9}$
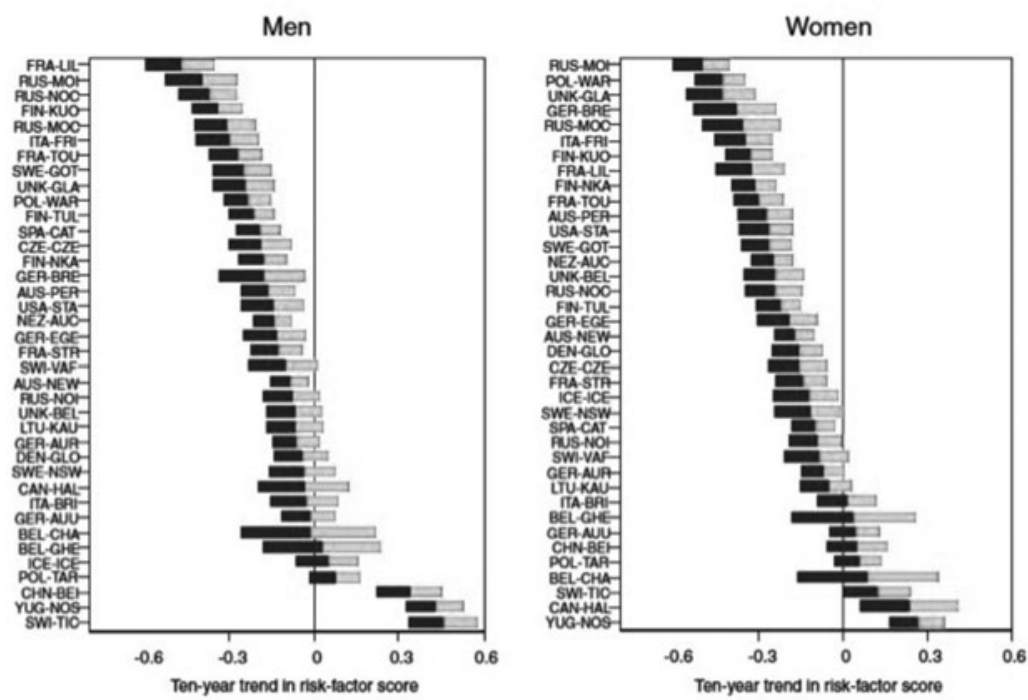

Fig. 7. Ten-year change in average coronary risk-factor score.

Source: MONICA Monograph and Multimedia Sourcebook, $2003 .{ }^{9}$ 


\section{BEYOND THE MONICA CORE}

The combined results as of 2002 present only part of the picture. ${ }^{9}$ MONICA trained a cadre of cardiovascular epidemiologists in 21 countries in hypothesis-driven studies, based on a population perspective, collecting data according to agreed definitions, with transparent quality assurance procedures and results. Many MONICA centers continue collaboration through the Helsinki Data Centre, (now a European reference center for population health surveys) in the MOnica Risk, Genetics, Archiving and Monograph (MORGAM) Project, coordinated from Belfast. ${ }^{43}$ This has collected data from MONICA and other survey populations with archived material and follow-up to study other components of risk through genetic material and biomarkers.

The MONICA dataset is rather underexploited, but one late novel analysis pooled the changes in blood pressure (by contrast most MONICA analyses were based on scatter plots). This showed that the average decline in blood pressure in MONICA populations between their first and final surveys occurred at all levels, being the same for the $20^{\text {th }}, 50^{\text {th }}$ and $80^{\text {th }}$ centiles and the mean. This suggested that the decline was from overall mass population change, rather than from increasing medication of those in the population diagnosed as hypertensive (in the upper centiles) and on treatment. ${ }^{44}$

While the study was ongoing, many centers presented their local information in published manuscripts. Following the end of MONICA many of the centers, with their own funding, continued to use the established methods for a number of different studies. These included extension of the follow-up of the cohorts, new population survey groups and expansion of the age window. MONICA was also compared to other ongoing cohort studies and the data were used to evaluate other diseases.

The ancillary studies have been particularly productive. For example, the study of stroke, which involved 15 centers, has published regularly on their findings. ${ }^{45,46}$ Studies of thrombotic and inflammatory markers have been presented. ${ }^{47}$ Environmental factors, such as temperature and barometric pressure and their effects on CVD, have been published by the French group along with the association of diet with smoking. ${ }^{48,49}$ The use of complementary medications in Northern Sweden has been the subject of an analysis..$^{50}$ With the wealth of information and stored data, including blood samples, work will continue on the original MONICA datasets.

Many centers have extended various elements of the MONICA protocol up through the current period with governmental and/or foundation support. These centers have continued to register and follow-up myocardial infarction rates in their survey areas. ${ }^{51-54}$ Others continued the surveillance 
and expanded their age window, usually to age 74 , to more closely track the migration of CVD to older ages. ${ }^{51,54,55}$ Some centers have performed additional population surveys using the same sampling frame. These have included the groups in northern Sweden and France. ${ }^{56,57}$ Some MONICA centers have combined to look at specific areas, such as alcohol, ${ }^{58}$ or with other cohorts, such as the Münster Heart Study (PROCAM) evaluating lipids, ${ }^{59}$ and finally some centers have begun to look at other diseases in the cohort, such as diabetes. ${ }^{60,61}$

Many of the centers were unable to continue the costly and high level of surveillance originally performed by MONICA and now complicated by a change to ICD10 classifications, the advent of new biomarkers for diagnosis of myocardial infarction, and changes in the clinical terminology of acute coronary events. ${ }^{24}$ However, there are outcomes and experience lasting beyond the original study. MONICA has provided the standards and platform for population-based disease surveillance of mortality, morbidity and population risk.

\section{FUTURE OF SURVEILLANCE IN 2011}

The Institute of Medicine in the US unveiled a framework for surveillance of cardiovascular and chronic lung diseases at the instigation of the NHLBI and the CDC. Their charge was to develop a framework for building a national chronic disease surveillance system focused primarily on cardiovascular and pulmonary diseases that is capable of providing data for analysis of race, ethnic, socioeconomic and geographic region disparities in incidence and prevalence, functional outcomes, measured risk factors and clinical care delivery. The committee recognized that current surveillance data was not standardized, could not be linked across sources and was often not accessible. They also recognized that the advent of widespread use of electronic health records (EHR) had great potential for collecting and analyzing these data but that there were serious barriers with different systems and technologies. The recommendations were for the establishment of systems to address the needs for actionable indicators of cardiovascular and pulmonary health in the population across the nation and within vulnerable subgroups. ${ }^{10}$

There are also ongoing efforts in Europe to continue population surveillance. The European Society of Cardiology (ESC) established a number of ongoing registries over the past decade under the title Euro Heart Survey. ${ }^{6}$ These include clinical data collection in multiple countries according to a standardized format with coordination at the European Heart House in Nice, France. There are surveys on: Acute Coronary Syndromes, 
Adult Congenital Heart Disease, Angina Pectoris, Arrhythmias, Coronary Interventions, Diabetes, Heart Failure, Preventive Practice (Eurospire) and Valvular Heart Disease.

There are also ongoing efforts to establish a European Health Examination Survey. From 2003-2008, the European Union funded a study of the Feasibility of a European Health Examination Survey (FEHES) through the Programme of Community Action in Public Health. ${ }^{63}$ This initial effort, led by MONICA investigators from the coordinating center in Finland, is currently in a pilot phase (2009-2011). ${ }^{64}$

The spirit and accomplishments of MONICA continue to contribute.

Acronyms list:

CVD = Cardiovascular disease

MONICA = The WHO Multinational MONItoring of Trends and Determinants in CArdiovascular Disease Project

NHLBI $=$ The National Heart, Lung and Blood Institute

Acknowledgements: Much of the material and all the graphics except Figure 1 are taken, with permission, from the MONICA Monograph and Multimedia Sourcebook published in 2003 and available from the World Health Organization, but also on the internet at: http://www.ktl.fi/monica/public/monograph.html. The author thanks Professor Hugh Tunstall-Pedoe for his comments and editorial assistance.

\section{REFERENCES}

1. Havlik RJ, Feinleib M, editors. Proceedings of the Conference on the Decline in Coronary Heart Disease Mortality, October 24-25, 1978. Washington, DC: National Heart, Lung and Blood Institute, 1979, NIH publication No. 79-1610, DHES.

2. Dawber TR. The Framingham Study: The Epidemiology of Atherosclerotic Disease. Cambridge, MA: Harvard University Press; 1980.

3. Keys A. Seven Countries: A Multivariate Analysis of Death and Coronary Heart Disease. Cambridge, MA and London, England: Harvard University Press; 1980.

4. Brown SA, Hutchinson R, Morrisett J, Boerwinkle E, Davis CE, Gotto AM Jr, et al. Plasma-lipid, lipoprotein cholesterol, and apoprotein distributions in selected United States communities: the Atherosclerosis Risk in Communities (ARIC) Study. Arteriosclerosis and Thrombosis. 1993;13:1139-58.

5. Gillum RF, Hannan PJ, Prineas RJ, Jacobs DRE Jr, Gomez-Marin O, Luepker RV, et al. Coronary heart disease mortality trends in Minnesota, 1960-1980: the Minnesota Heart Survey. Am J Public Health. 1984;74:360-2.

6. Luepker RV, Murray DM, Jacobs DR, Mittelmark MB, Bracht N, Carlaw R, et al. Community education for CVD prevention: risk factor changes in the Minnesota Heart Health Program. Am J Pub Health. 1994;84:1383-93. 
7. Winkleby MA, Taylor CB, Jatulis D, Fortmann SP. The long-term effects of a cardiovascular disease prevention trial: the Stanford Five-City Project. Am J Pub Health. 1996;86:1773-9.

8. Carleton RA, Lasater TM, Assaf AR, Feldman HA, McKinlay S. The Pawtucket Heart Health Program: community changes in cardiovascular risk factors and projected disease risk. Am J Pub Health. 1995;85:777-85.

9. Tunstall-Pedoe $\mathrm{H}$ (editor), for the WHO MONICA Project. MONICA Monograph and Multimedia Sourcebook. World Health Organization, Geneva, 2003.

10. Institute of Medicine. A Nationwide Framework for Surveillance of Cardiovascular and Chronic Lung Diseases. IOM. Washington, DC: The National Academies Press; 2011.

11. Butler WJ, Ostrander LD Jr, Carman WJ, Lamphiear DE. Mortality from coronary heart disease in the Tecumseh Study: long-term effect of diabetes mellitus, glucose tolerance and other risk factors. Am J Epidemiol. 1985;121:541-7.

12. Costas R, Garciapalmieri MR, Nazario E, Sorlie PD. Relation of lipids, weight and physical activity to incidence of coronary heart disease: Puerto Rico Heart Study. Am J Cardiol. 1978;42:653-8.

13. World Health Organization Regional Office for Europe. Myocardial infarction community registers, Copenhagen, 1976 (Public Health in Europe 5).

14. Uemura K, Pisa Z. Trends in cardiovascular disease mortality in industrialized countries since 1950. World Health Stat Q 1988;41:156-78.

15. Higgins M, Luepker RV, editors. Trends and determinants of coronary heart disease mortality: international comparisons. Int J Epidemiol. 1989;18:S1235.

16. Madans JH, Cox CS, Kleinman JC, Makuc D, Feldman JJ, Finucane FF, et al. 10 years after NHANES-1: mortality experience at initial follow-up, 198284. Pub Health Reports. 1986;101:474-81.

17. Winkleby, MA, Feldman, HA, Murray, DM. Joint analysis of three U.S. community intervention trials for reduction of cardiovascular disease risk. J Clin Epidemiol. 1997;50:645-58.

18. WHO MONICA Project. MONICA Manual. (1998-1999). 31 March 1999. Available from URL: http://www.ktl.fi/publications/monica/manual/index. htm (Accessed 2 August, 2011).

19. Prineas RJ, Crow RS, Blackburn HW. The Minnesota Code Manual of Electrocardiographic Findings: Standards and Procedures for Measurement and Classification. J. Wright, 1982.

20. WHO MONICA Project. MONICA Quality assessment reports. MONICA Web Publications 2-18. 12 August, 2010. Available from URL: http://www.ktl.fi/ publications/monica/index.html (Accessed 2 August, 2011). 
21. Tunstall-Pedoe H, Kuulasmaa K, Amouyel P, Arveiler D, Rajakangas AM, Pajak A, for the WHO MONICA Project. Myocardial infarction and coronary deaths in the World Health Organization MONICA Project. Registration procedures, event rates, and case-fatality rates in 38 populations from 21 countries in four continents. Circulation. 1994;90:583-612.

22. Asplund K, Tuomilehto J, Stegmayr B, Wester PO, Tunstall-Pedoe H, for the WHO MONICA Project. Diagnostic criteria and quality control of the registration of stroke events in the WHO MONICA project. Acta Med Scan Suppl 1988;728:26-39.

23. Thorvaldsen P, Asplund K, Kuulasmaa K, Rajakangas AM, Schroll M, for the WHO MONICA Project. Stroke incidence, case fatality, and mortality in the WHO MONICA Project. Stroke. 1995;26:361-7.

24. Tunstall-Pedoe H. Descriptions and definitions of myocardial infarction personal reminiscences and a challenge. Int J Epidemiol. 2011;40:147-9.

25. Mähönen M, Cepaitis Z, Kuulasmaa K, for the WHO MONICA Project. Quality assessment of acute coronary care data in the WHO MONICA Project. February 1999. Available from URL: http://www.ktl.fi/publications/monica/ accqa/accqa.htm, URN:NBN:fi-fe19991081 (Accessed 2 August, 2011).

26. DeGaudemaris R, Folsom AR, Prineas RJ, Luepker RV. The random-zero versus the standard mercury sphygmomanometer: a systematic blood pressure difference. Am J Epidemiol. 1985;121:282-90.

27. Tunstall-Pedoe H, Kuulasmaa K, Mahonen M, Tolonen H, Ruokokoski E, Amouyel P. Contribution of trends in survival and coronary-event rates to changes in coronary heart disease mortality: 10-year results from $37 \mathrm{WHO}$ MONICA Project populations. Lancet 1999;353:1547-57.

28. Kuulasmaa K, Tunstall-Pedoe H, Dobson A, Fortmann S, Sans S, Tolonen H, Evans A, Ferrario M, Tuomilehto J. Estimation of contribution of changes in classic risk factors to trends in coronary-event rates across the WHO MONICA Project populations. Lancet 2000;355:675-87.

29. Tunstall-Pedoe H, Vanuzzo D, Hobbs M, Mahonen M, Capaitis Z, Kuulasmaa $\mathrm{K}$, Keil U. Estimation of contribution of changes in coronary care to improving survival, event rates, and coronary heart disease mortality across the WHO MONICA Project populations. Lancet 2000;355:688-700.

30. The WHO MONICA Website. 19 September, 2009. URL: http://www.ktl.fi/ monica/ (Accessed 2 August, 2011).

31. Chambless LE, Dobson AJ, Patterson CC, Raines B. On the use of a logistic risk score in predicting risk of coronary heart disease. Stat Med. 1990;9:38596.

32. Kulathinal SB, Kuulasmaa K, Gasbarra D. Estimation of an errors-in-variables regression model when the variances of the measurement errors vary between the observations. Stat Med. 2002;21:1089-101. 
33. Kuulasmaa K, Dobson A, for the WHO MONICA Project. Statistical issues related to following populations rather than individuals over time. Bulletin of the International Statistical Institute: Proceedings of the 51st Session; 1997 Aug 18-26; Istanbul, Turkey. Voorburg: International Statistical Institute; 1997. Book 1; 295-8. Also available from URL: http://www.ktl.fi/ publications/monica/isi97/isi97.htm (Accessed 15 December 2011).

34. Tolonen H, Dobson A, Kulathinal S, for the WHO MONICA Project. Effect on trend estimates of the difference between survey respondents and nonrespondents: results from 27 populations in the WHO MONICA Project. Eur J Epidemiol. 2005;20:887-98.

35. Wolf HK, Kuulasmaa K, Tolonen H, Sans S, Molarius A, Eastwood BJ, for the WHO MONICA Project. Effect of sampling frames on response rates in the WHO MONICA risk factor surveys. Eur J Epidemiol. 2005;20:293-9.

36. Tolonen H, Ferrario M, Kuulasmaa K, for the WHO MONICA Project. Standardization of total cholesterol measurement in population surveys pre-analytic sources of variation and their effect on the prevalence of hypercholesterolaemia. Eur J Cardiovasc Prev Rehabil. 2005;12:257-67.

37. Barnett A, Sans S, Salomaa V, Kuulasmaa K, Dobson A, for the WHO MONICA Project. The effect of temperature on systolic blood pressure. Blood Press Monit. 2007;12:195-203.

38. Salomaa V, Dobson A, Miettinen H, Rajakangas A-M, Kuulasmaa K, for the WHO MONICA Project. Mild myocardial infarction - a classification problem in epidemiologic studies. J Clin Epidemiol. 1997;50:3-13.

39. Hense HW, Koivisto A-M, Kuulasmaa K, Zaborskis A, Kupsc W, Tuomilehto J, for the WHO MONICA Project. Assessment of blood pressure measurement quality in the baseline surveys of the WHO MONICA Project. J Hum Hypertens. 1995; 9:935-46.

40. Tolonen H, Dobson A, Kulathinal S, for the WHO MONICA Project. Assessing the quality of risk factor survey data: lessons from the WHO MONICA Project. Eur J Cardiovasc Prev Rehabil. 2006;13:104-14.

41. Waterhouse J, Muir CS, Correa P, Powell I, eds. Cancer incidence in five continents. Lyon, IARC, 1976. Vol 3, p.456.

42. Tunstall-Pedoe H. Is acute coronary heart disease different in different countries in the two sexes: lessons from the MONICA Project. Cardiovasc Risk Factors. 1996;6:254-61.

43. Evans A, Salomaa V, Kulathinal S, Asplund K, Cambien F, Ferrario M, Percia M, Peltonen L, Shields D, Tunstall-Pedoe H, Kuulasmaa K , for the MORGAM Project. MORGAM (an international pooling of cardiovascular cohorts). Int J Epidemiol 2005; 34: 21-7.

44. Tunstall-Pedoe H, Connaghan J, Woodward M, Tolonen H, Kuulasmaa K, for the WHO MONICA Project. Pattern of declining blood pressure across replicate population surveys of the WHO MONICA project, mid-1980s to mid-1990s, and the role of medication. BMJ. 2006;332:629-35. 
45. Asplund K, Bonita R, Kuulasmaa K, Rajakangas A-M, Feigin V, Schädlich H, et al., for the WHO MONICA Project. Multinational comparisons of stroke epidemiology - evaluation of case-ascertainment in the WHO MONICA stroke study. Stroke. 1995;26:355-60.

46. Sarti C, Stegmayr B, Tolonen H, Mähönen M, Tuomilehto J, Asplund J, for the WHO MONICA Project. Are changes in mortality from stroke caused by changes in stroke event rates or case fatality? Results from the WHO MONICA Project. Stroke. 2003;34:1833-41.

47. Yarnell J, McCrum E, Rumley A, Patterson C, Salomaa V, Lowe G, et al., on behalf of the MONICA Optional Haemostasis Study Investigators. Association of European population levels of thrombotic and inflammatory factors with risk of coronary heart disease: the MONICA Optional Haemostasis Study. Eur Heart J. 2005;26:332-42.

48. Nuttens MC, Romon M, Ruidavets JB, Arveiler D, Ducimetiere P, Lecerf JM, et al. Relationship between smoking and diet: the MONICA-France project. J Internal Med. 1992;231:349-56.

49. Danet S, Richard F, Montaye M, Beauchant S, Lemaire B, Graux C, et al. Unhealthy effects of atmospheric temperature and pressure on the occurrence of myocardial infarction and coronary deaths: A 10-year survey: the LilleWorld Health Organization MONICA Project (Monitoring Trends and Determinants in Cardiovascular Disease). Circulation. 1999;100:e1-e7.

50. Nilsson M, Trehn G, Asplund K. Use of complementary and alternative medicine remedies in Sweden. A population-based longitudinal study within the northern Sweden MONICA Project. J Internal Med. 2001;250:225-33.

51. Isaksson RM, Jansson JH, Lundblad D, Näslund U, Zingmark K, Eliasson M. Better long-term survival in young and middle-aged women than in men after a first myocardial infarction between 1985 and 2006: an analysis of 8630 patients in the Northern Sweden MONICA Study. BMC Cardiovasc Disorders. 2011;11:1.

52. Lundblad D, Holmgren L, Jansson JH, Näslund U, Eliasson M. Gender differences in trends of acute myocardial infarction events: the Northern Sweden MONICA Study 1985-2004. BMC Cardiovasc Diseases. 2008;8:17.

53. Briffa T, Hickling S, Knuiman M, Hobbs M, Hung J, Sanfilippo FM, et al. Long term survival after evidence based treatment of acute myocardial infarction and revascularization: follow-up of population based Perth MONICA cohort, 1984-2005. BMJ. 2009;338:b36.

54. Sans S, Puigdefábregas A, Paluzie G, Monterde D, Balaguer-Vintró I. Increasing trends of acute myocardial infarction in Spain: the MONICA-Catalonia Study. Eur Heart J. 2005;26:505-15.

55. Kuch B, Wende R, Barac M, von Scheidt W, Kling B, Greschik C, et al. Prognosis and outcomes of elderly (75-84 years) patients with acute myocardial infarction 1-2 years after the event - AMI-elderly study of the MONICA/KORA Myocardial Infarction Registry. Int J Cardiology. 2011;149:205-10. 
56. Pigeyre M, Dauchet L, Simon C, Bongard V, Bingham A, Arveiler D, et al. Effects of occupational and educational changes on obesity trends in France: the results of the MONICA-France survey 1986-2006. Prev Med. 2011;52:305-9.

57. Eriksson M, Holmgren L, Janlert U, Jansson JH, Lundblad D, Stegmayr B, et al. Large improvements in major cardiovascular risk factors in the population of northern Sweden: the MONICA study 1986-2009. J Internal Med. 2010;269:219-31.

58. Imhof A, Woodward M, Doering A, Helbecque N, Loewel H, Amouyel P, et al. Overall alcohol intake, beer, wine, and systemic markers of inflammation in western Europe: results from three MONICA samples (Augsburg, Glasgow, Lille). Eur Heart J. 2004;25:2092-100.

59. Hense HW, Schulte H, Löwel H, Assmann G, Keil U. Framingham risk function overestimates risk of coronary heart disease in men and women from Germany - results from the MONICA Augsburg and the PROCAM cohorts. Eur Heart J. 2003;24:937-45.

60. Beck JA, Meisinger C, Heier M, Kuch B, Hörmann A, Greschik C, et al. Effect of blood glucose concentrations on admission in non-diabetic versus diabetic patients with first acute myocardial infarction on short- and long-term mortality (from the MONICA/KORA Augsburg Myocardial Infarction Registry). Am J Cardiol. 2009;104:1607-12.

61. McDonagh TA, Woodward M, Morrison CE, McMurray JJV, Tunstall-Pedoe H, Lowe GDO, et al. Helicobacter pylori infection and coronary heart disease in the North Glasgow MONICA population. Eur Heart J. 1997;18:1257-60.

62. Euro Heart Survey. Available from URL: http://www.escardio.org/ guidelinessurveys/ehs/Pages/welcome.aspx (Accessed 26 September, 2011).

63. Feasibility of a European Health Examination Survey. Available from URL: http://www.ktl.fi/fehes/index.html (Accessed 26 September, 2011).

64. Levy RI, Causes of the decrease in cardiovascular mortality. Am J Cardiol. 1984;54:7C-13C. 